Forum 2016 · 31:279

DOI 10.1007/s12312-016-0117-6

Online publiziert: 12. Juli 2016

๑) Springer-Verlag Berlin Heidelberg 2016

\section{Stiftung :::::: Deutsche :: Krebsgesellschaft}

Am 1. Juni 2016 fand in Berlin unter dem Motto „Zurück im Leben“ der 2. German Cancer Survivors Day (GCSD) statt. Er wurde von der Deutschen Krebsstiftung - der Stiftung der Deutschen Krebsgesellschaft - initiiert und durchgeführt. Auf einer Bühne im Hauptbahnhof Berlin standen von 10 bis 16 Uhr 18 Langzeitüberlebende sowie ihre Strategien fürs Überleben und für ein Leben mit und nach Krebs im Mittelpunkt.

Ziel des GCSD ist es, neben den gesellschaftlich breit diskutierten Themen Prävention und Therapien für Krebserkrankungen das Augenmerk auf das Überleben mit all seinen möglichen Folgen zu lenken. Es geht auch darum - und deshalb findet die Veranstaltung an einem so öffentlichen Ort wie dem Hauptbahnhof statt -, Mut zu machen, im Falle einer Erkrankung aktiv seinen Heilungsprozess und sein Leben zu gestalten. Der GCSD fand in Zusammenarbeit mit der DKG und der Berliner Krebsgesellschaft statt.

\section{Kontakt}

\section{Deutsche Krebsstiftung}

c/o Deutsche Krebsgesellschaft

Iris Meumann

Tel.: 030 3229329-23

meumann@krebsgesellschaft.de

\title{
2. German Cancer Survivors Day
}

\section{Deutsche Krebsstiftung lenkt Aufmerksamkeit auf Langzeitüberlebende}

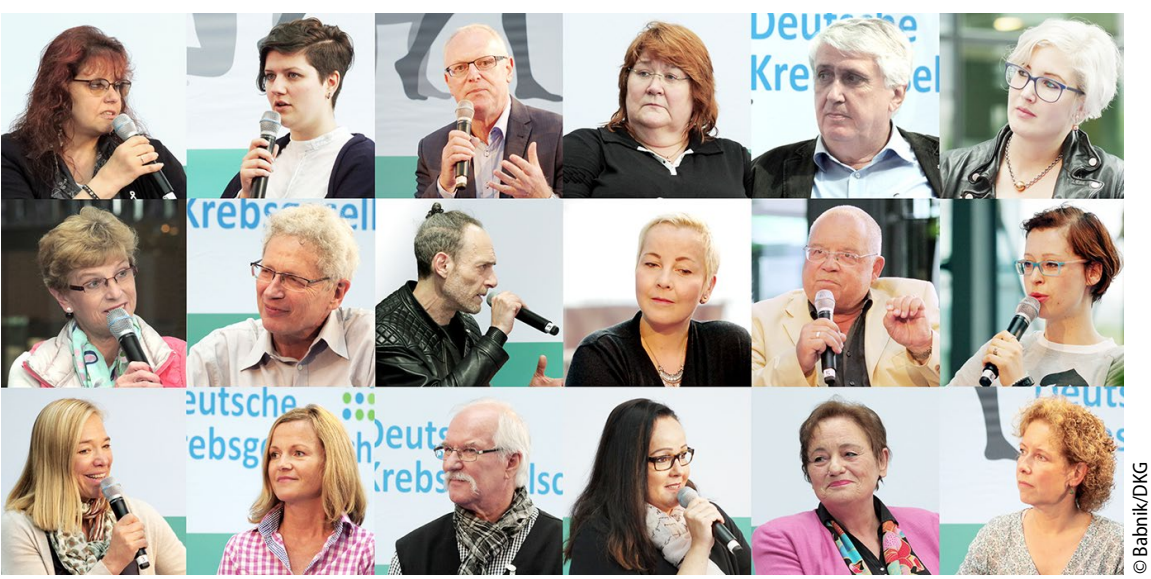

Abb. 1 \ 18 Langzeitüberlebende nach Krebs erzählten ihre Geschichte

Abb. $2 \sim \ln$ jeweils halbstündigen moderierten Gesprächsrunden kamen auf der Bühne im Hauptbahnhof Berlin Langzeitüberlebende und Experten aus Politik und Gesellschaft zu Wort

Abb. 3 > Trotz des bewegten Veranstaltungsortes blieben Passanten und Reisende stehen und hörten zu - der GCSD soll allen Mut machen, sein Leben aktiv zu gestalten
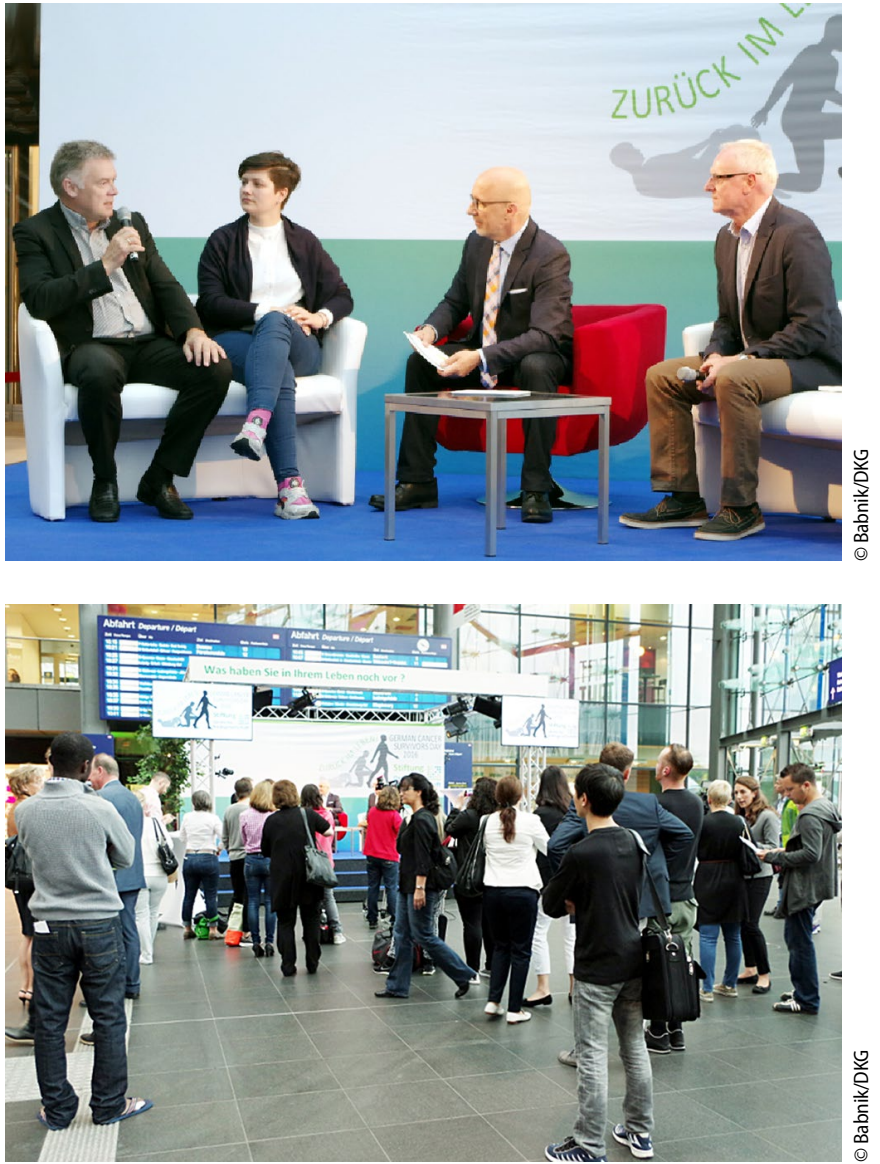